\title{
Calculation methods of glass parapets in aluminium clamping profiles
}

\author{
Youri Baidjoe $\mathbb{D}$ - Bert Van Lancker • \\ Jan Belis $(1)$
}

Received: 16 February 2018 / Accepted: 19 April 2018 / Published online: 27 April 2018

(C) The Author(s) 2018

\begin{abstract}
This study aims to investigate and assess the analytical calculation methods which are applicable to glass parapets. Specifically it is focused on glass parapets, which are continuously clamped along their lower edge in an aluminium profile, without the addition of a (structural) handrail. The starting point of the research are the current codes of practice regarding glass parapets. The objectives are to investigate the limitations of the current methods, to develop new methods and to test whether these are applicable, taking into account the standards of several European countries. Codes and standards from the Netherlands, Belgium, the United Kingdom and Germany are analysed and applied to the calculation methods, to identify and analyse the differences. Subsequently, a series of static load tests have been performed to determine the spring stiffness of the aluminium parapet clamping profiles, such that they can be applied in new analytical calculation methods. The long-term value of this research is to present more accurate calculation methods which can be applied to continuously supported glass parapet, accounting for different parameters, such as the supporting effect of sealing rubbers and the application
\end{abstract}

Y. Baidjoe $(\varangle) \cdot$ J. Belis

Eindhoven University of Technology, Eindhoven,

The Netherlands

B. Van Lancker · J. Belis

Ghent University, Ghent, Belgium

e-mail: Bert.VanLancker@ugent.be

J. Belis

e-mail: Jan.Belis@ugent.be depth of fixation wedges. Finally, recommendations are made to improve common calculation methods.

Keywords Glass parapet - Glass balustrade . Calculation method - Ultimate/serviceability limit state $\cdot$ Spring stiffness

\section{Introduction}

The material glass has been applied within the built environment for centuries. Due to its transparent nature, glass has been an inspiring building material for architects and engineers. Over the last decades a plethora of fully transparent skins has been built. Still, the loadbearing capacity of glass has yet to reach its full potential.

The current contribution focuses on glass parapets. The latter can be divided into several categories, depending on the support type and the type of connection. This research concentrates on glass parapets with three free edges. The parapets are supported by specific aluminium profiles wherein the glass panes are continuously clamped along their lower edge. Over the last decades, the usage of glass parapets has drastically increased. However, due to the application of different calculation methods in practice, a large variety in the dimensioning of glass parapets is occurring. This lack of clarity has led to a need for research within these calculation methods. 
Fig. 1 Differently supported glass parapets: a parapet continuously clamped along its edge; $\mathbf{b}$ infill panel glass parapet; $\mathbf{c}$ point supported glass parapet. (www.crystaliteinc. com 2017)

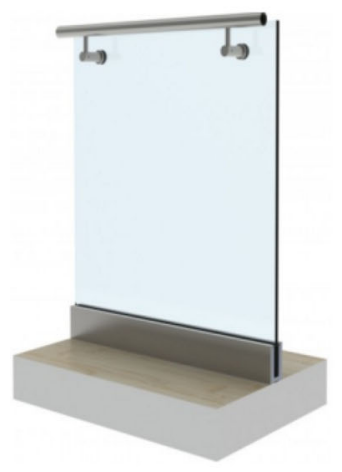

(a)

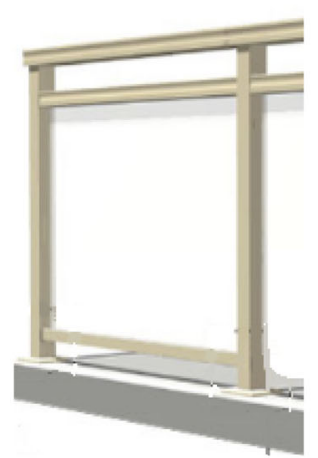

(b)

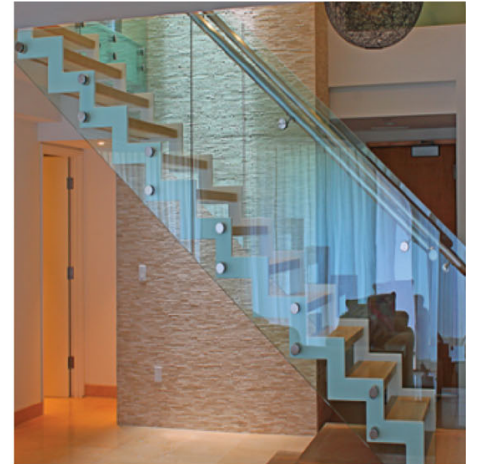

(c)
In the past research has been performed on the structural capacity of free-standing glass balustrades (Goosen 2007). This research is focused on the maximum loading capacity of free-standing glass parapets in regard to the South African and international design standards. Additionally, previous research has shown that the determination of spring stiffness using a quasistatic load test is possible (Van Lancker et al. 2014). However, the combination of mechanical schematizations including spring stiffness to calculate the stress and deformation of a glass parapet in an aluminium clamping profile has not been performed.

\section{Objectives}

The goal of this research is to compare and evaluate the design methods for glass parapets in aluminium clamping profiles and to develop improved methods. Making use of analytical and experimental research techniques these methods are evaluated. The objective of these analyses is to obtain a validation of the analytical mechanical schematisations. This method should keep safety in regard, yet try to dimension the parapets as economic as possible. Summing up, the objectives of the research are:

- To identify key parameters and determine the magnitude of their effects on the response of glass parapets to static loading;

- To determine which calculation methods correspond best to experimental evidence;

- To make recommendations to the existing mechanical schematisations of glass parapets clamped in aluminium parapet profiles.

\section{Scope}

Several types of glass parapets are commonly used. Three typical categories of glass parapets may be distinguished, based on the way the glass is supported: (i) continuously supported along two or more edges (infill panel); (ii) point supported; and (iii) continuously clamped along the lower edge.

When glass is used as an infill panel, the glass itself is not the primary structure. Although the glass in this case obviously needs to be able to withstand loads (e.g. people, wind, impact,...), most of the force is carried by the surrounding material, which is the primary structural element. In the other cases, the glass takes a more structural role. This research is focused on glass parapets, which are (only) continuously clamped along the lower edge in an aluminium profile (see Sect. 3; Fig. 1).

\section{Aluminium parapet clamping systems}

\subsection{Classification of aluminium clamping profiles}

The aluminium parapet clamping profiles are classified in several categories. Their names (F-, U- and Yprofiles) are derived from the shape of the clamping profile, as depicted in Fig. 2.

An additional variable on the classification of the profile is the location where the profile is mounted on the floor. More specifically, corresponding mounting types are either top mounted (the profile is mounted on top of the floor, see Fig. 2a, c) or side mounted (the profile is mounted to the side of the floor, see Fig. 2b, d). This results in the full 4-type classification system used within this research, as summarised in Table 1. 


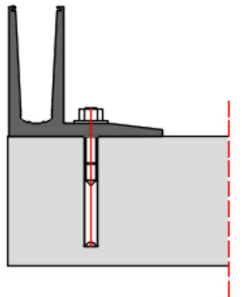

(a)

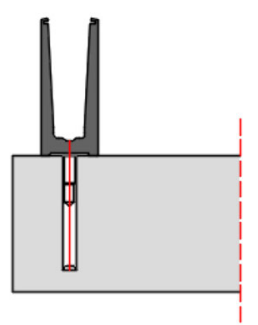

(c)

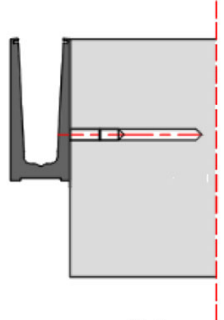

(b)

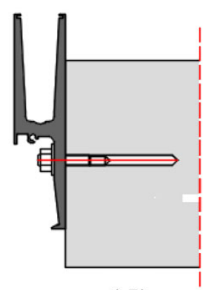

(d)
Fig. 2 Classification of the parapet profile types: a F-profile; $\mathbf{b}$ U-profile, side mounted c U-profile, top mounted; d Y-profile

\subsection{Other components used}

A glass parapet consists of several different components as illustrated in Fig. 3. The numbering of the components corresponds with the building order during construction of the parapet. These components each have an individual role to add to the practical application of the profile. The parapet clamping profile is used to position the glass pane and provide strength and stiffness to the system. It provides the connection between the floor and the parapet and is used for the clamping of the glass. The inlay profile prevents direct contact between metal and glass and provides tight clamping at the bottom and at one lateral side of the glass. The wedges are placed at the other lateral side of the glass to fix it in the parapet profile and to prevent any contact between glass and metal. The components noted in this section may vary in shape and size depending on the

Table 1 Mounting types of the aluminium parapet profiles considered, based on profile shape and mounting location

\begin{tabular}{lll}
\hline Profile & Top mounted & Side mounted \\
\hline F-profile & (a) & \\
U-profile & (c) & (b) \\
Y-profile & & (d) \\
\hline
\end{tabular}

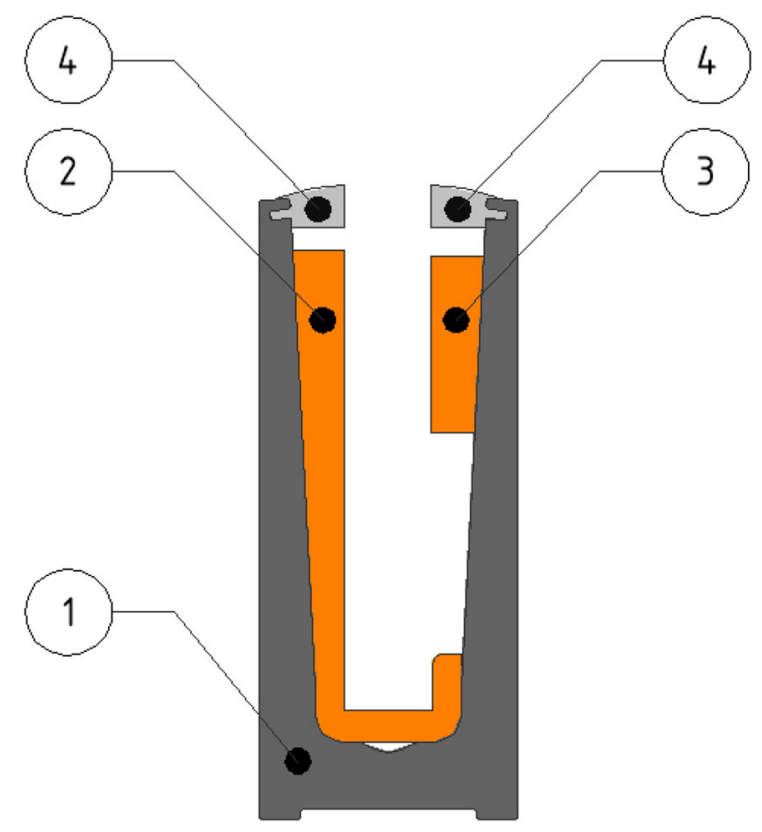

Fig. 3 Cross-section of a parapet clamping system: (1) parapet clamping profile; (2) inlay profile; (3) wedge; (4) rubbers

manufacturer, but their functioning is principally the same. Relevant characteristics of the different components are listed in Table 2.

\section{Standards and codes}

This section gives an introduction to the standards and codes that are applicable to glass parapets in The Netherlands, Belgium, Germany and the United Kingdom.

\subsection{Loading on glass parapets}

The loading is described according to the NEN-EN 1991 National Annex (2011). The parapet is divided into two zones, namely zone a and zone $\mathrm{b}$ as depicted in Fig. 4.

The loading on the parapet consists of two types of loading, namely (i) a continuous (line) load $\mathrm{q}_{\text {rep }}(\mathrm{kN} / \mathrm{m})$ at the top of the parapet in zone a, and (ii) a concentrated load $\mathrm{F}_{\text {rep }}(\mathrm{kN})$ in zone $\mathrm{a}$, zone $\mathrm{b}$ or zone $\mathrm{a}+\mathrm{b}$ of the parapet.

The magnitude of these loads, according to the classification of spaces for instance according to the Dutch national annex, is given in Table 3. For other countries, 
Table 2 Characteristics of parapet clamping profile components

\begin{tabular}{llll}
\hline Component & Material & Elastic modulus (N/mm $\left.{ }^{2}\right)$ & Poisson's ratio $(-)$ \\
\hline Parapet clamping profile & Aluminium 6063 T6 & 68,900 & 0.33 \\
Inlay profile & Acrylnitril butadiene styrol & 2300 & 0.35 \\
Wedge(s) & Acrylnitril butadiene styrol & 2300 & 0.35 \\
Rubbers & Ethylene propylene diene monomer & $10-100^{\mathrm{a}}$ & $0.48-0.50^{\mathrm{a}}$ \\
Glass & Soda lime silica glass & 70,000 & 0.23 \\
\hline
\end{tabular}

${ }^{a}$ Varies depending on composite

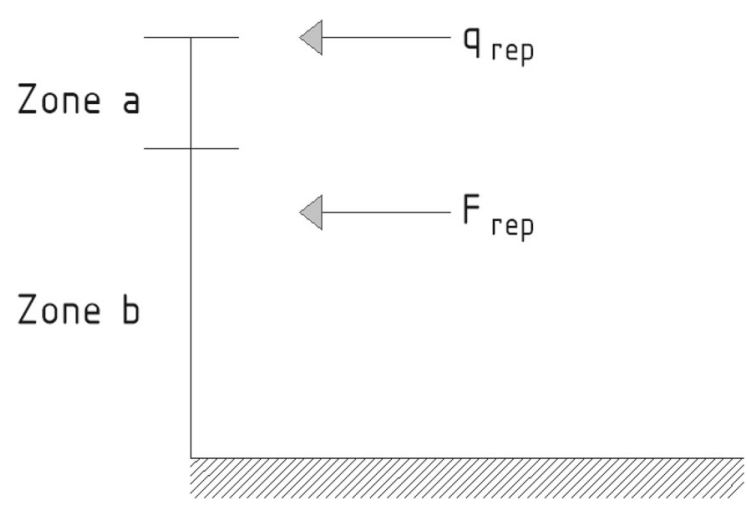

Fig. 4 Parapet loading according to NEN-EN 1991

the loads may differ according to the national regulations.

\subsection{Serviceability limit state and ultimate limit state}

For the Ultimate Limit State (ULS), in all of the above mentioned countries, the occurring stress due to the prescribed load has to be lower than the design value of the resistance. This is done by means of a unity check including several safety factors. For the Serviceability Limit State (SLS) the maximum deflection is prescribed in the corresponding code. The absolute values are listed in Table 4.

Comparing the four countries mentioned above, several differences and similarities are found.

In Ultimate Limit State, the approach is very similar. Even though the formulae differ, ultimately they all apply the same method to determine whether or not the ultimate limit state is met. This is done through means of the characteristic strength of glass, the occurring stress in the glass, several safety factors and a unity check (UC) for the stress. However, in Serviceability Limit State more differences are seen. For instance, the maximum deflection of a parapet in Belgium is $15 \mathrm{~mm}$ whereas it is $25 \mathrm{~mm}$ in the United Kingdom. Contrary to the other countries in Germany no Serviceability Limit State criterion is described. Such significant variation within the deflection limits within Europe creates a difficult situation for designers, suppliers and manufacturers. The currently applied deflection limits seem to be derived from deflection limits for other materials, such as concrete, steel or timber. These materials have a different behaviour and the dimensions and shape of the material in which they are applied are different. This questions the basis of current deflection limits for glass parapets continuously clamped along their lower edge. Additionally, the mechanical schematisation is not prescribed in any of the European or National Codes (see Sect. 6).

When designing according to any standards, the reader is advised to always consult the original version, as additional proofs might be applicable.

\section{Analytical models}

The analytical research consists of several mechanical schematisations of glass parapets. As shown in Fig. 5, multiple options are possible to schematise a glass parapet.

Although, "encastre" and "horizontal support" are the models which are currently most commonly applied in practice, each model is briefly discussed below.

\subsection{Encastre}

This schematisation assumes the glass is fully clamped within the profile. The length $\mathrm{L}$ is often chosen as the length that protrudes above the aluminium parapet clamping profile, also known as the unsupported 
Table 3 Overview of the loads on parapets in NEN-EN 1991 (2011) according to the Dutch national annex

\begin{tabular}{|c|c|c|c|c|c|c|c|c|}
\hline \multirow[t]{3}{*}{ Spaces } & \multirow{2}{*}{\multicolumn{2}{|c|}{$\begin{array}{l}\mathrm{q}_{\text {rep }} \\
\text { Prescribed height } \\
\text { or zone a }\end{array}$}} & \multicolumn{6}{|l|}{$\mathrm{F}_{\text {rep }}$} \\
\hline & & & \multicolumn{2}{|c|}{$\begin{array}{l}\text { Prescribed height } \\
\text { or zone a }\end{array}$} & \multicolumn{2}{|c|}{ Zone b } & \multicolumn{2}{|l|}{ Zone $\mathrm{a}+\mathrm{b}$} \\
\hline & Load (kN/m) & Duration (min) & Load (kN) & Duration (min) & Load & Duration & Load $(\mathrm{kN})$ & Duration (h) \\
\hline $\begin{array}{l}\text { Non-collective } \\
\text { space with resi- } \\
\text { dential functions }\end{array}$ & 0.3 & 1 & 0.5 & 1 & 0.35 & $10 \mathrm{~s}$ & 0.2 & 24 \\
\hline $\begin{array}{l}\text { Collective space } \\
\text { with residential } \\
\text { function }\end{array}$ & 0.5 & 1 & 1 & 1 & 0.35 & $10 \mathrm{~s}$ & 0.2 & 24 \\
\hline $\begin{array}{l}\text { Non-collective } \\
\text { space of a cel- } \\
\text { function }\end{array}$ & 0.5 & 1 & 1 & 1 & 0.5 & $10 \mathrm{~s}$ & 0.3 & 24 \\
\hline $\begin{array}{l}\text { Remaining utility } \\
\text { functions }\end{array}$ & 3 & 5 & 1 & 5 & 0.7 & $5 \min$ & 0.5 & $7 \times 24$ \\
\hline $\begin{array}{l}\text { Remaining } \\
\text { spaces }\end{array}$ & 0.8 & 5 & 1 & 5 & 0.7 & $5 \min$ & 0.5 & $7 \times 24$ \\
\hline
\end{tabular}

Table 4 Overview of the codes

\begin{tabular}{|c|c|c|c|c|c|c|}
\hline Country & Loading standard & Mechanical schematisation & Additional requirements & ULS & SLS & Height (mm) \\
\hline Netherlands & EN 1991 & Not prescribed & National building decree & UC & $20 \mathrm{~mm}$ & $1000-1200$ \\
\hline Belgium & EN 1991 & Not prescribed & & $\mathrm{UC}$ & $15 \mathrm{~mm}$ & $1100-1200$ \\
\hline Germany & EN 1991 & Not prescribed & $\begin{array}{l}\text { LSG }^{\mathrm{a}} \\
\text { Min 10.10.4 glass } \\
\text { Continuous handrail }\end{array}$ & $\mathrm{UC}$ & - & Max 1100 \\
\hline United Kingdom & EN 1991 & Not prescribed & & UC & $25 \mathrm{~mm}$ & $1000-1200$ \\
\hline
\end{tabular}

${ }^{a}$ Laminated safety glass

length. The unsupported length generally is $1000 \mathrm{~mm}$, in the case of an $1100 \mathrm{~mm}$ glass pane. The maximum occurring moment and deflection of the parapet are calculated with respectively Eqs. (1) and (2).

$$
\begin{aligned}
& M_{\max }=F L \\
& \delta=\frac{F L^{3}}{3 E I}
\end{aligned}
$$

Where I is the second moment of area about the weak axis of the glass pane, and $\mathrm{E}$ is the elastic modulus of the glass pane. In case laminated glass is used, approximate values could be used by calculating the bending stiffness based on an equivalent thickness as proposed by e.g. Galuppi and Royer-Carfagni (2014).

\subsection{Horizontal support}

Within this schematisation type the glass pane is supported by a horizontal support at 1/10 of the length of the protruding glass. This assumes an unsupported length of $1000 \mathrm{~mm}$. In the case of an unsupported length of $1200 \mathrm{~mm}$, the ratio is $1 / 12 \mathrm{~L}$. The horizontal support is assumed to be the top edge of the aluminium parapet clamping profile, where the glass is clamped between the rubbers, which are inserted in the profile. The maximum occurring moment and deflection of the parapet are calculated with respectively Eqs. (1) and (3).

$\delta=\frac{11 F L^{3}}{30 E I}$ 


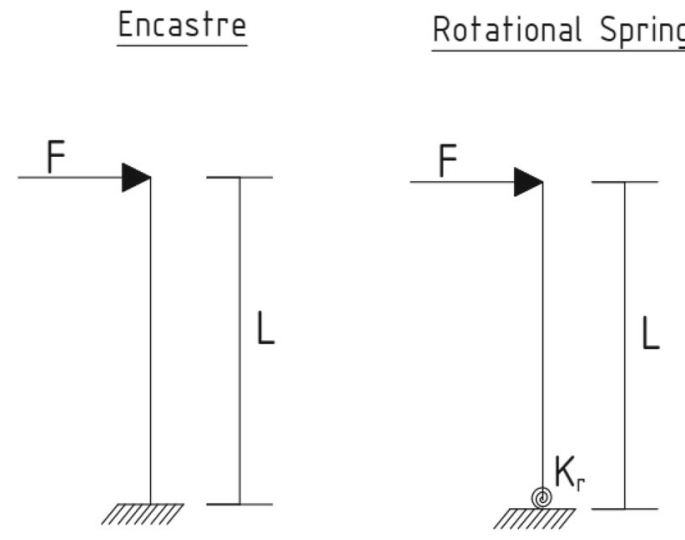

Fig. 5 Mechanical schematizations of glass parapets

\subsection{Rotational spring}

The schematisation of the aluminium glass parapet in this case consists of a glass pane, which is schematised as a beam with a length L. Added to this schematisation is a rotational spring with a spring stiffness $\mathrm{K}_{\mathrm{r}}$. The spring stiffness can be determined through experimental testing (Van Lancker et al. 2014). The maximum occurring moment and deflection of the parapet are calculated with respectively Eqs. (1) and (4).

$\delta=\frac{F L^{3}}{3 E I}+\frac{F L^{2}}{K_{r}}$

\subsection{Translational spring}

The translational spring scheme consists of a glass pane, which is schematised as a beam. The length $\mathrm{L}$ is the protruding height of the glass above the parapet profile. Within this research this is $1000 \mathrm{~mm}$. The beam is supported by a translational spring at $1 / 10 \mathrm{~L}$. The translational spring has a spring stiffness $\mathrm{K}_{\mathrm{t}}$, which can be determined through experimental testing (Van Lancker et al. 2014). The maximum occurring moment and deflection of the parapet are calculated with respectively Eqs. (1) and (5).

$\delta=\frac{11}{30} \frac{F L^{3}}{E I}+\frac{121 F}{K_{t}}$
Horizontal Support

Tгаnslational spring
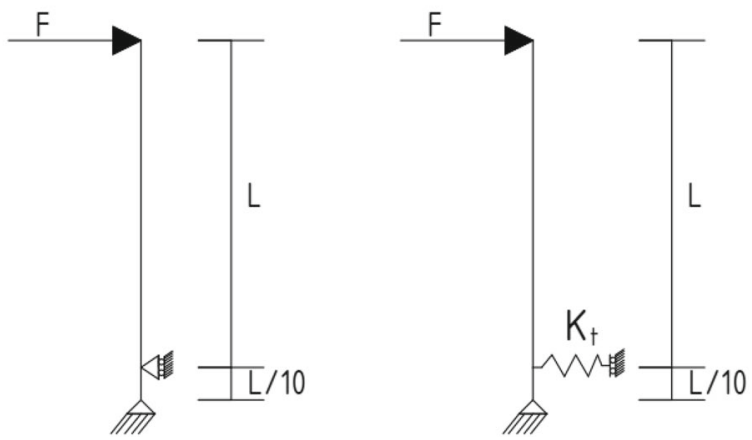

\subsection{Effective length}

In practice the length $\mathrm{L}$ of the system is taken as $1000 \mathrm{~mm}$. However, in reality the actual length of the system may be different. The length of the glass pane often is $1100-1300 \mathrm{~mm}$, while the free height of the glass within the profile is $1000-1200 \mathrm{~mm}$. Yet the glass is able to bend within the profile; this results in the actual length of the system being different from the free height of the glass.

\subsection{Compression of the rubber}

Currently the analytical model consists of two terms that contribute to the displacement of the glass at the outer end, namely the bending of the glass and the displacement due to deformation of the parapet profile.

This is not complete yet, since the rotation of the aluminium parapet clamping profile does not fully comply with the displacement at that point. This is due to the compression of the rubber at that specific point. The compression of the rubber causes the glass pane to tilt sideways, adding an additional displacement. Consequently, the compression of the rubber is taken into account, see Eq. (12).

A crucial aspect of the compression of the rubber is the Poisson's ratio of the rubber. This is due to the rubber most likely experiencing an hydrostatic stress state. The material properties of the rubber are of great importance. However, due to the irregular shape of the 
rubbers and the varying composites applied by the different manufacturers, this was not unified.

\subsection{Discussion analytical models}

Firstly, the analytical research clearly shows that there is a large disparity between the different formulas. This results in the need to research the most accurate mechanical schematisation for continuously supported glass parapets at the edge.

Secondly, the moment in each of the mechanical schematisations complies with the other formulae. Thus the occurring bending stress does not vary depending on the type of schematisation that is used.

Finally, the additional variables, such as the effective length of the glass and the compression of the rubber, can significantly influence the results regarding the deflection of the parapet. So, to obtain a realistic accurate solution, they are also taken into account.

\section{Determination of the spring stiffness}

Two types of spring stiffnesses are determined, namely the rotational spring stiffness $\left(K_{r}\right)$ and the translational spring stiffness $\left(K_{t}\right)$.

\subsection{Rotational spring stiffness}

The displacement is measured at three locations during the quasi-static load test on the top edge of the parapet clamping profile, as depicted in Figs. 6 and 10. The deformation of the parapet clamping profile is schematically depicted in Fig. 7.

First, the average displacement of these three nodes is determined. The displacement is converted to an angle $\phi$ in Eq. (6).

$\phi=T A N^{-1}\left(\frac{\delta_{\text {Profile }}}{H_{\text {profile }}}\right)$

The total moment $M$ is calculated using the total load $F$ and the length of the system $L$ in Eq. (1).

$M_{\max }=F L$
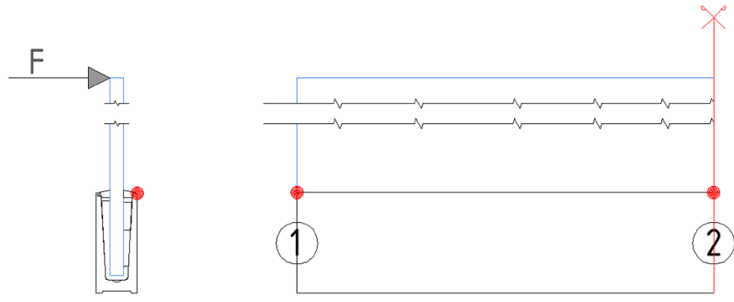

Fig. 6 Indication of the locations where the displacement is measured

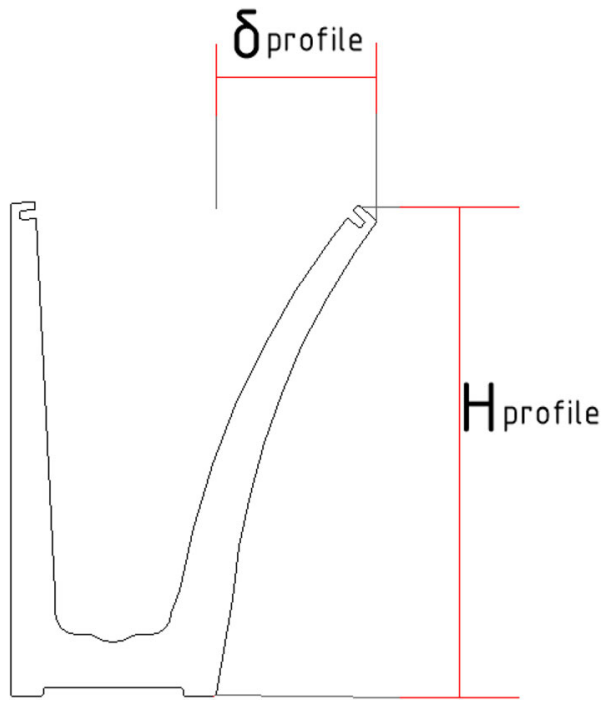

Fig. 7 Deformed parapet profile

Followed by the determination of the spring stiffness in Eq. (7).

$\frac{M_{\max }}{\phi}=K_{r}$

\subsection{Translational spring stiffness}

The displacement is measured at three locations during the quasi-static load test on the top edge of the parapet clamping profile, as depicted in Figs. 6 and 10. The average displacement ( $\delta_{\text {profile }}$ ) of these three locations is determined. Followed by the determination of the reaction force at the location of the translational spring, according to Eq. (8).

$R B H=11 \times F_{\text {total }}$ 
Table 5 Overview of the different profiles

\begin{tabular}{llllll}
\hline Profile type & Manufacturer & & & \\
\cline { 2 - 5 } & AMG & Samples $(\mathrm{m})$ & OnLevel & Samples & Q-railing \\
\hline F-profile, top & Quick Premium & 4 & TL 3010 & 5 & Easy Glass Pro F \\
U-profile, top & Simple Premium & 4 & TL 6010 & 5 & Easy Glass Pro U \\
U-profile, side & Simple Premium & 4 & TL 6011 & 5 & Easy Glass Pro U \\
Y-profile, side & Standard Advanced & 4 & TL 3011 & 5 & Easy Glass Pro Y \\
\hline
\end{tabular}

Fig. 8 General test setup of the quasi-static load test
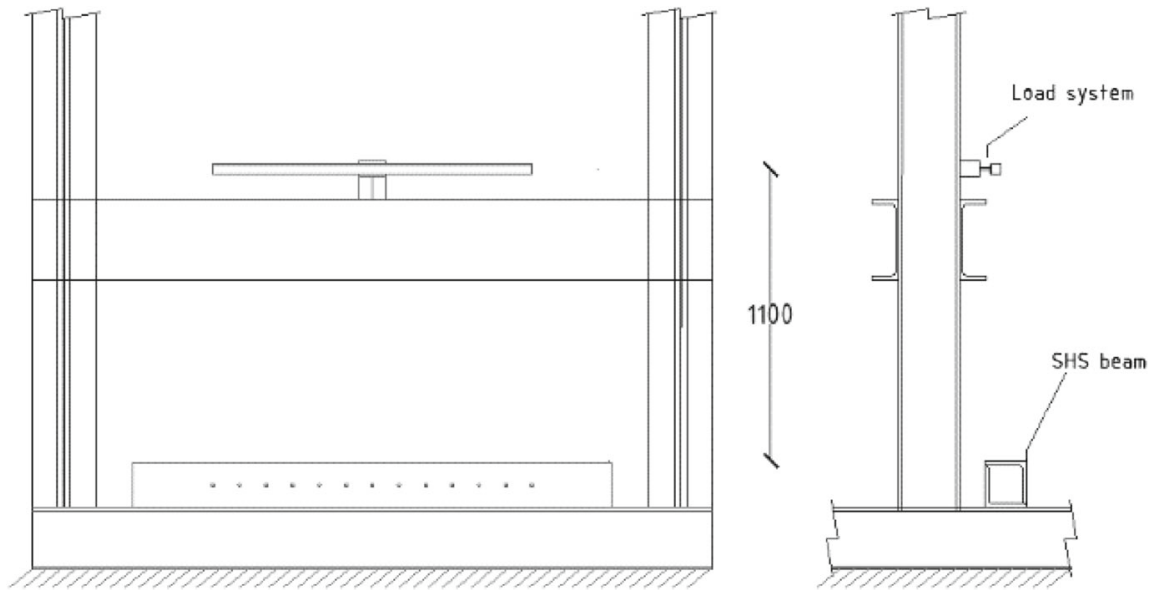

Combining the average displacement and the reaction force, the translational spring stiffness $\left(K_{t}\right)$ is determined according to Eq. (9).

$K_{t}=\frac{R B H}{\delta_{\text {profile }}}$

\section{Experimental research-quasi-static load test}

For the empirical determination of the spring stiffnesses of the aluminium parapet clamping profiles a full series of quasi-static load tests is performed. The goal of these experiments is to determine the displacement of the glass when loaded for validation of the analytical models and to determine the rotational stiffness of the aluminium parapet clamping profiles.

The results of the experiment are essential for the evaluation of the feasibility of the different analytical models used in practice with the addition of the proposed new mechanical schematisation.

During the experiment the length of the aluminium parapet test samples is $1000 \mathrm{~mm}$. In practice the length of glass parapets is longer, yet the mechanical schematisation does not change.

The glass placed within the aluminium parapet clamping profile has dimensions of $1000 \mathrm{~mm} \times 1100 \mathrm{~mm}$ $\times 15 \mathrm{~mm}$.

The experiment is a displacement-controlled setup, because we wanted each glass parapet to reach approximately the same displacement, independent of the amount of force applied to the glass parapet. The ultimate displacement values measured at the top of the glass pane during the experiment varied from 45 to $50 \mathrm{~mm}$.

\subsection{Glass pane}

Several glass panes of $1100 \mathrm{~mm} \times 1000 \mathrm{~mm}$ have been used during the experiments. The glass panes consist of monolithic glass with a nominal thickness of $15 \mathrm{~mm}$. Laminated glass has several parameters which influence the mechanical behaviour such as temperature and load duration. These influences are removed by using monolithic glass. This is acceptable, as it is common practice to calculate laminated glass by 


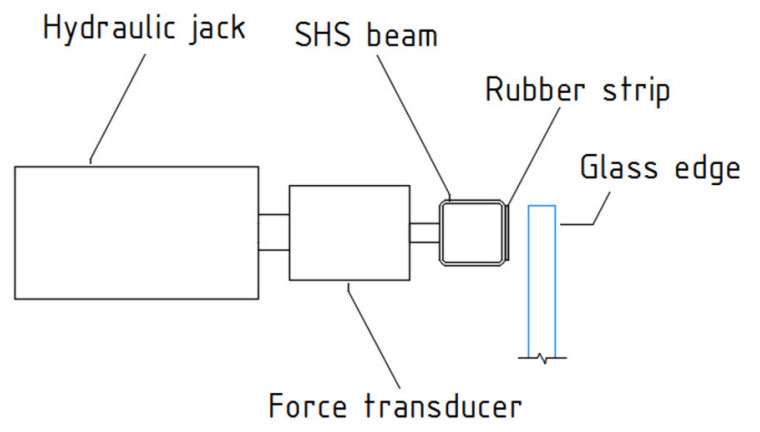

Fig. 9 Load system setup

means of an equivalent monolithic thickness using an (enhanced) effective thickness method (Galuppi and Royer-Carfagni 2014). In Chapter 11 a case study with a laminated glass pane making use of an effective thickness method is described.

\subsection{Test specimens}

Aluminium parapet clamping profiles of three manufacturers have been analytically and experimentally investigated in this research (AMG, OnLevel and Qrailing). An overview of the profiles used during the experimental part is shown in Table 5.

\subsection{Test setup}

The test setup is shown in Fig. 8. It consists of a rigid steel frame provided with two HEA240 columns, two UNP100 beams and one SHS composite beam. On the UNP100 beams the load system is connected. The load system consists of SHS beam, load cell, hydraulic jack and a hydraulic pump.

The load is introduced by means of a hydraulic pump. The hydraulic pump is manually operated to increase the applied load by the hydraulic piston. The hydraulic jack is connected to the load cell. The load cell measures the difference in resistance within the load cell, which can be converted to the actual load. The load cell is connected to the SHS-beam, which converts the hydraulic load to a line load on the glass. A rubber strip is placed on the SHS-beam, to prevent any metal-to-glass contact (Fig. 9).

Linear variable differential transducers (LVDT's) are used to measure the displacement at a specific location and strain gauges are used to determine the strain

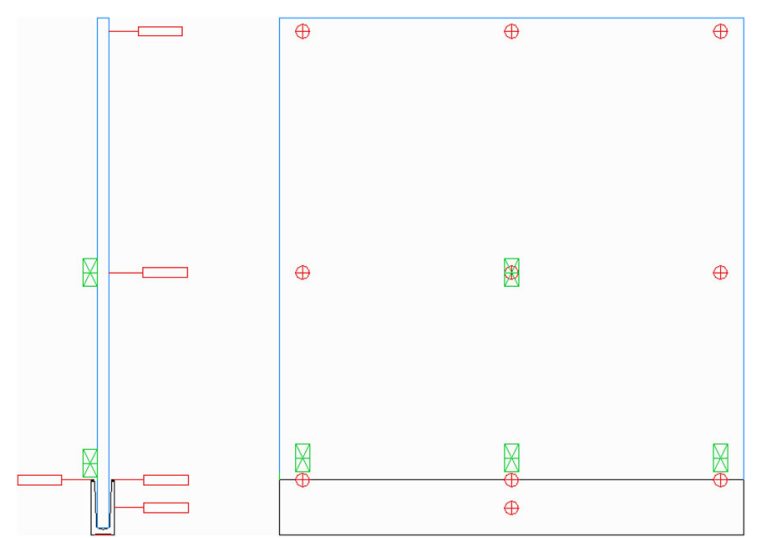

Fig. 10 Experimental test setup 2: (left) side view; (right) front view

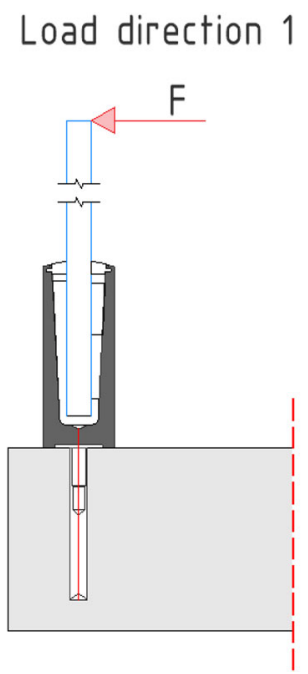

Load direction 2

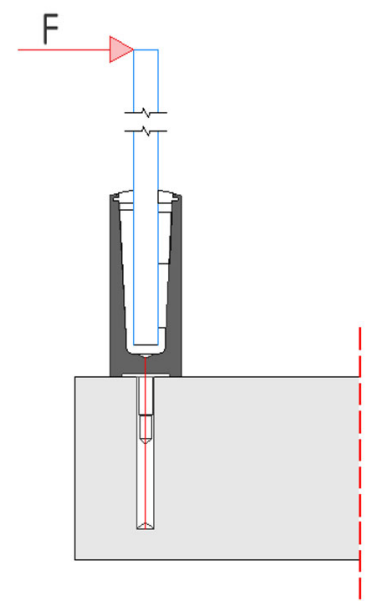

Fig. 11 Schematization of the load directions

on the glass, as illustrated in Fig. 10. The LVDT's are depicted by the circles in the front-view and by rectangles with a line to the glass pane in the side-view. The strain gauges are indicated by rectangles with a star in both the front- and side-view (Fig. 11).

\subsection{Results}

In Fig. 12, shown below the overview of the rotational stiffnesses of the three manufacturers are shown. The purpose of the histogram is that the difference in magnitude of spring stiffness of the manufacturers can be compared. For this reason only the rotational stiffnesses will be shown. The translational stiffnesses would show 
Fig. 12 Histogram rotational stiffness in load direction one

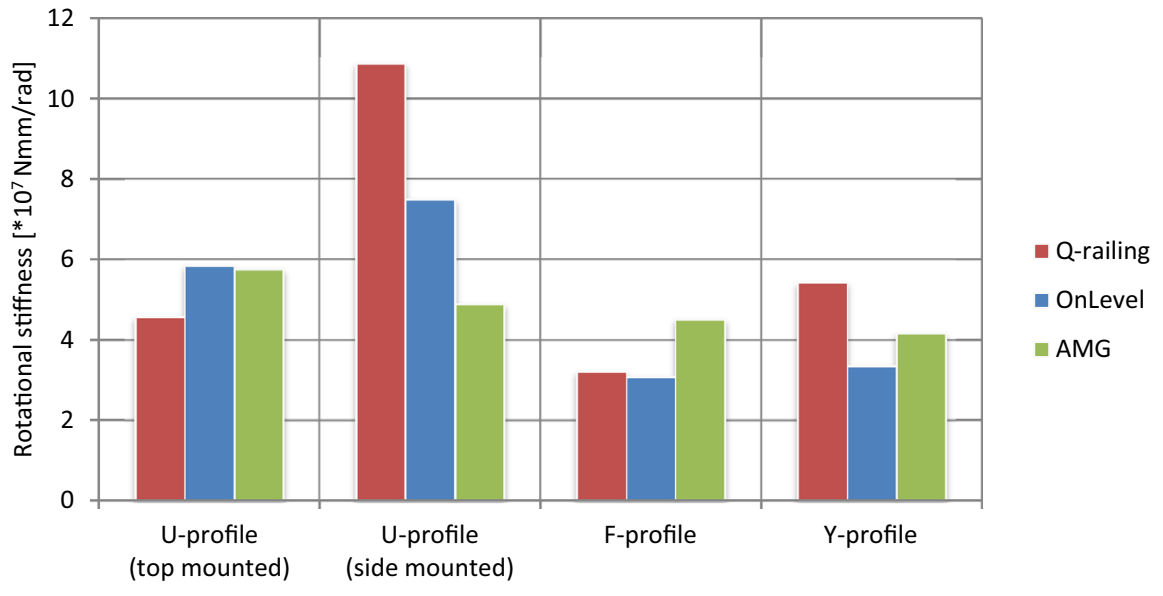

the exact same histograms, yet only with a different scale. This is due to both the stiffnesses being derived from the same displacement data.

\section{Comparison between the analytical and experimental data}

The displacement obtained from the quasi-static load test and the spring stiffnesses obtained from the quasistatic load test are compared with the displacement values which are determined making use of the analytically determined formulae.

The displacement of the glass during the experiment is composed of several contributions, namely;

1. The displacement according to the static calculation formula $\left(\delta_{\text {formula }}\right)$;

2. The displacement caused by the rotation of the SHS-beam $\left(\delta_{\text {beam }}\right)$;

3. The displacement caused by the compression of the rubber $\left(\delta_{R \_ \text {Glass }}\right)$.

These components together can be used to compare the analytical calculation of the displacement to the experimentally obtained displacement.

The total displacement is calculated according to Eq. 10, which takes three different terms into account.

$\delta_{\text {Total }}=(1) \delta_{\text {Formula }}+(2) \delta_{\text {beam }}+(3) \delta_{R_{-} \text {Glass }}$

The first term $\delta_{\text {formula }}$ is calculated according to Eq. (4).
Displacement caused by rotation of the SHS-beam is calculated in Eq. (11).

$\delta_{\text {beam }}=\phi_{\text {beam }} \times\left(H_{\text {profile }}+H_{\text {beam }}\right)$

Displacement caused by the rubber compression is determined by Eq. (12).

$\delta_{R \_ \text {glass }}=\delta_{\text {rubber }} \times \alpha_{\text {ratio }}$

where

$\alpha_{\text {ratio }}=\frac{L_{\text {Glass_protruding }}}{L_{\text {Glass_insertion }}}$

For the displacement caused by the compression of the rubber, it is assumed that a glass pane with a length of $1100 \mathrm{~mm}$ is used, with an insertion depth ( $\left.L_{\text {Glass_insertion }}\right)$ of $100 \mathrm{~mm}$ in the aluminium parapet profile. This results in a protruding glass length ( $L_{\text {Glass_protruding }}$ ) of $1000 \mathrm{~mm}$.

The results of the comparison making use of Qrailing U-profile top mounted are listed in Table 6.

\subsection{Conclusions comparison between the analytical and experimental data}

From Table 6, it can clearly be seen that the encastred and horizontal support mechanical schematisations are an underestimation of the actual occurring displacements. Even with the addition caused by the compression of the rubber these mechanical schematisations fall short. Both the rotational spring and translational 
Table 6 Overview displacement Q-railing U-profile top mounted
aThe displacement values of the rubbers have been approximated by the compression of the rubbers in QR-YP-LD1/2

\begin{tabular}{lcccccc}
\hline Sample & \multicolumn{2}{l}{ Displacement $(\mathrm{mm})$} & & & & \\
\cline { 2 - 4 } & $\begin{array}{l}\text { Horizontal } \\
\text { Support }\end{array}$ & $K r$ & $K t$ & Rubber $^{\mathrm{a}}$ & Experiment \\
\hline $\begin{array}{l}\text { Load direction one } \\
1\end{array}$ & 13.71 & 15.08 & 35.24 & 40.76 & 3.99 & 47.32 \\
2 & 23.01 & 25.31 & 40.80 & 44.96 & 6.47 & 46.87 \\
3 & 21.01 & 23.11 & 41.70 & 46.36 & 5.15 & 46.15 \\
4 & 15.20 & 16.72 & 44.45 & 50.62 & 5.10 & 47.69 \\
5 & 25.00 & 27.50 & 43.12 & 47.35 & 5.32 & 47.76 \\
Load direction two & & & & & \\
1 & 21.86 & 24.04 & 38.30 & 41.44 & 4.99 & 47.71 \\
2 & 24.33 & 26.77 & 38.82 & 41.14 & 8.19 & 48.52 \\
3 & 22.85 & 25.13 & 38.63 & 42.78 & 9.01 & 47.94 \\
4 & 22.68 & 24.95 & 34.69 & 37.26 & 7.40 & 46.91 \\
5 & 21.86 & 24.04 & 38.30 & 41.44 & 4.99 & 47.71 \\
\hline
\end{tabular}

spring achieve a significantly higher accuracy in the estimation of the displacement.

Concluding, it can be said that the rotational and translational mechanical schematisations offer a more accurate method than those currently used in practice, such as the encastred or the horizontal support schematisations.

Using the encastred or horizontal support mechanical schematisation results in an underestimation of the displacement varying from 25 to $35 \mathrm{~mm}$, which is an underestimation of $50-70 \%$, respectively. The deviation is dependent on the profile type and load direction.

The new methods making use of springs do require additional effort and are slightly more complicated, yet the significant increase in accuracy does make these methods a valuable replacement for the current calculation methods.

\section{Comparison of the experimental and analytical stress}

In this section a comparison between the analytically calculated stress and the experimentally determined stress is given for a Q-railing Y-profile.

In Table 7, the stress comparison of the Q-railing Easy Glass Pro " $Y$ " is shown. In columns four and five, the experimental respectively the analytical stresses are given. The final two columns consist of the abso- lute deviation in stress and the percentage deviation between the experimentally obtained stress and the analytically calculated stress.

The stress comparison results seem accurate. The average deviation in load direction one is approximately $7 \%$ and in load direction two it is $2 \%$. These results are accurate enough for the analytical calculation to be assumed correct.

10.1 Conclusions comparison of the experimental and analytical stress

The currently applied method to determine the stresses in glass parapets is accurate enough to offer a good representation of reality.

\section{Static calculation example}

An example of a static calculation is done for the determination of the glass thickness in a glass parapet mounting system. The purpose of this case-study is to show the practical approach to the design process of a glass parapet.

To show that there is a difference in the choice for the glass thickness, which is highly dependent on the serviceability limit state, several European standards and codes are applied to the design process.

These countries are The Netherlands, Belgium, United Kingdom and Germany. 
Table 7 Overview stress Q-railing Easy Glass Pro "Y"

\begin{tabular}{lllllll}
\hline $\begin{array}{l}\text { Load } \\
\text { direction }\end{array}$ & Sample & $\begin{array}{l}\text { Maximum } \\
\text { force }(\mathrm{N})\end{array}$ & $\begin{array}{l}\text { Stress } \\
\text { exper- } \\
\text { iment } \\
\left(\mathrm{N} / \mathrm{mm}^{2}\right)\end{array}$ & $\begin{array}{l}\text { Stress } \\
\text { analytical } \\
\left(\mathrm{N} / \mathrm{mm}^{2}\right)\end{array}$ & $\begin{array}{l}\text { Difference } \\
\left(\mathrm{N} / \mathrm{mm}^{2}\right)\end{array}$ & Difference (\%) \\
\hline LD1 & 1 & 1205 & 31.66 & 33.46 & -1.8 & 5.85 \\
& 2 & 1168 & 31.31 & 32.43 & -1.12 & 3.57 \\
& 3 & 1353 & 33.58 & 37.57 & -3.99 & 11.88 \\
& 4 & 1251 & 31.87 & 34.74 & -2.87 & 9.01 \\
& 5 & 1261 & 33.26 & 35.01 & -1.75 & 5.26 \\
LD2 & 1 & 1639 & 46.35 & 45.51 & 0.84 & 1.81 \\
& 2 & 1528 & 44.42 & 42.43 & 1.99 & 4.48 \\
& 3 & 1593 & 44.81 & 44.23 & 0.58 & 1.29 \\
& 4 & 1612 & 44.32 & 44.76 & -0.44 & 0.99 \\
& 5 & 1621 & 44.28 & 45.00 & -0.72 & 1.63 \\
\hline
\end{tabular}

Table 8 Variables for the static calculation

\begin{tabular}{ll}
\hline Glass type & $\begin{array}{l}\text { Soda-lime silica } \\
\text { Thermally toughened }\end{array}$ \\
Glass treatment & $10.10 .4(\mathrm{PVB})$ \\
Glass laminate & 70,000 \\
E-modulus glass $\left(\mathrm{N} / \mathrm{mm}^{2}\right)$ & 120 \\
Mechanical strength $\left(\mathrm{N} / \mathrm{mm}^{2}\right)$ & 1000 \\
Height of the system $(\mathrm{mm})$ & 1000 \\
Load on the system $(\mathrm{N} / \mathrm{m})$ & 0.3 \\
Shear-coefficient & 1000 \\
Total load $(\mathrm{N})$ & \\
\hline
\end{tabular}

\subsection{Case study}

As an example, a case study is presented below, The parapet is assumed to be continuously supported along its bottom edge by a Q-railing Easy Glass Pro U. The variables of the parapet are depicted in Table 8 .

Before the static calculation can be performed, the effective thickness of the laminated glass pane is required. The type of glass that will be used within this setup as a reference point is 10.10 .4 glass. The method to determine the effective thickness for the static calculation is the method proposed by the NEN2608 (2014). The static calculation needs to fulfil two requirements;

- The maximum stress may not exceed the mechanical strength of glass;

- The maximum displacement may not exceed the prescribed standard, see Table 9.
Table 9 Overview of the standards for the serviceability limit state

\begin{tabular}{lll}
\hline Country & Standard & $\begin{array}{l}\text { Maximum } \\
\text { displacement } \\
(\mathrm{mm})\end{array}$ \\
\hline Netherlands & NEN 2608 (2014) & 20 \\
Belgium & NBN B03-004 (2015) & 15 \\
Germany & DIN 18008 (2013) & - \\
United Kingdom & BS 6180 (2011) & 25 \\
\hline
\end{tabular}

\subsection{Ultimate limit state}

Effective thickness of 10.10.4 glass in ULS according to NEN2608 (2014) is $16.58 \mathrm{~mm}$.

Determination of the moment using Eq. 1.

$$
M=1000 \times 1000=1.0 \times 10^{6}[\mathrm{Nmm}]=1(\mathrm{kNm})
$$

Determination of the elastic section modulus

$$
W=\frac{1}{6} \times 1000 \times(16.58)^{2}=4.56 \times 10^{4}\left(\mathrm{~mm}^{3}\right)
$$

Determination of the second moment of inertia

$I=\frac{1}{12} \times 1000 \times(16.58)^{3}=3.79 \times 10^{5}\left(\mathrm{~mm}^{4}\right)$

Determination of the bending stress

$I=\frac{1}{12} \times 1000 \times(16.58)^{3}=3.79 \times 10^{5}\left(\mathrm{~mm}^{4}\right)$ 
Unity check for the bending stress

$$
\begin{aligned}
& \frac{\sigma_{M ; E d}}{\sigma_{M ; R d}} \leq 1 \\
& \frac{21.83}{87.5} \leq 1=O K
\end{aligned}
$$

\subsection{Serviceability limit state}

Since the ultimate limit state has been fulfilled, the serviceability limit state has to be checked. As has been treated within this report, the deflection at the top of the glass pane can be calculated in four ways;

\section{Encastre}

Filling in Eq. 2. gives:

$\delta=\frac{1000 \times 1000^{3}}{3 \times 70,000 \times 3.79 \times 10^{5}}=12.56(\mathrm{~mm})$

\section{Horizontal support}

Filling in Eq. 3. gives:

$$
\begin{aligned}
& \delta=\frac{11 \times 1000 \times 1000^{3}}{30 \times 70,000 \times 3.79 \times 10^{5}}=13.82(\mathrm{~mm}) \\
& \text { Rotational spring }
\end{aligned}
$$

\section{Rotational spring}

The rotational stiffness value $K_{r}$ from Q-railing Uprofile Top mounted has been taken as an example. Filling in Eq. 4.

$$
\begin{aligned}
\delta & =\frac{1000 \times 1000^{3}}{3 \times 70,000 \times 3.79 \times 10^{5}}+\frac{1000 \times 1000^{2}}{5.39 \times 10^{7}} \\
& =12.56+18.55=31.11(\mathrm{~mm})
\end{aligned}
$$

\section{Translational spring}

The translational spring stiffness value $K_{t}$ from Qrailing U-profile Top mounted has been taken as an example. Filling in Eq. 5.

$$
\begin{aligned}
\delta & =\frac{11}{30} \times \frac{1000 \times 1000^{3}}{70,000 \times 3.79 \times 10^{5}}+\frac{121 \times 1000}{6.52 \times 10^{3}} \\
& =13.82+18.56=32.38(\mathrm{~mm})
\end{aligned}
$$

\subsection{Conclusion case study static calculation}

The serviceability limit state seems to be met when calculating with either the encastred mechanical schematisation or the horizontal support schematisation. This is because this type of calculation does not take in to account any effects due to deformation of different components except the glass bending contribution.
Yet when the rotational spring schematisation or the translational spring schematisation is used, the deflection limits of Belgium, the Netherlands and the United Kingdom are exceeded. It must be noted that these static calculations do not take the influence of the compression of the rubber into account.

\section{Conclusions}

In the present research of the analytical calculation of linearly supported glass parapets making use of aluminium parapet clamping profiles, the major influencing factors have been determined. The most important are the stiffness of the aluminium parapet clamping profile and the type of formula used for the calculation of the serviceability limit state. More detailed, the following conclusions can be drawn:

- In regard to the codes, the maximum deflection may be met; however, the methods which are applied most commonly, i.e. encastred and horizontal support, do not offer a good representation of reality.

- The calculation of the stresses within the glass of a continuously supported glass parapet is accurate enough with the mechanical schematisations currently applied within the built environment.

- The rotational spring and translational spring schematisation both lead to a high increase in accuracy for the determination of the displacement. However, the application of these schematisations is more complex, because the spring stiffnesses needs to be determined.

- The current Serviceability Limit State standards are not adequate for glass parapets which are continuously supported along the lower edge. If the rotational spring or translational spring mechanical schematisations were to be applied, the standards would have to be adjusted, such that the realistic displacement values are incorporated within the standard.

Acknowledgements The authors acknowledge the support of Scheuten Glas, Q-railing, OnLevel and AMG balustrades. The staff of the laboratory for Research on Structural Models of Ghent University, in particular Dennis Elias is acknowledged for his help with the experimental research.

\section{Compliance with ethical standards}

Conflict of interest The authors declares that they have no conflict of interest. 
Open Access This article is distributed under the terms of the Creative Commons Attribution 4.0 International License (http:// creativecommons.org/licenses/by/4.0/), which permits unrestricted use, distribution, and reproduction in any medium, provided you give appropriate credit to the original author(s) and the source, provide a link to the Creative Commons license, and indicate if changes were made.

\section{References}

BS 6180: Barriers in and about buildings (2011)

DIN-18008: Glass in Building-Design and Construction Rules-Part 4: Additional Requirements for Barrier Glazing. Available through: paper version (2013)

Galuppi, L., Royer-Carfagni, G.: Enhanced Effective Thickness of Multi-layered Laminated Glass. Compos. B Eng. 64, 202-213 (2014)
Goosen, A.: Master Thesis: Structural Capacity of Freestanding Glass, vol. 2, pp. 26-33. University of Stellenbosch, Stellenbosch (2007)

NBN B 03-004: Railings of buildings. Brussels: Bureau voor Normalisatie. Available through, NBN database (2015)

NEN-EN 1991 Eurocode 1: Actions on structures. Delft: Nederlands Normalisatie-instituut (2011)

NEN 2608: Vlakglas voor gebouwen, eisen en bepalingsmethoden. Delft: Nederlands Normalisatie-instituut (2014)

Van Lancker, B., Belis, J., De Corte, W.: Rotational stiffness of linear adhesive connections between cold-formed steel members and glass panels. In: GlassCon Global, Proceedings, pp. 729-746 (2014)

Publisher's Note Springer Nature remains neutral with regard to jurisdictional claims in published maps and institutional affiliations. 